training (M.R.C.Psych.). There will then follow a period of three years of higher training leading to accreditation by the JCHPT as a specialist in one or more of the five branches of psychiatry. Criteria for accreditation for the five branches of psychiatry have not yet been decided.

Accreditation by the JCHPT will be entirely separate from the EEC regulations for specialist registration. It is likely that if an individual is granted specialist status by the JCHPT he will more than fulfil the criteria for an EEC specialist but not vice versa.

It is clear that if such regulations are enforced they will have vitally important implications for trainees.
The JCHPT is still debating what form specialist accreditation in psychiatry will take if it is to be introduced.

We would like to receive views on this issue and it would be helpful if as many trainees as possible would write to David Gill, Chairman of the Working Party of Trainees, Knowle Hospital, Fareham, Hampshire, or to Chris Freeman, Secretary of APIT, Royal Edinburgh Hospital, Morningside Park, Edinburgh EHro 5HF. Some may prefer to discuss the matter with their local representative on the Working Party of Trainees, so that there can be a full debate at our next meeting.

David Girl

\title{
2. From the Secretary, Joint Committee on Higher Psychiatric Training
}

Any contribution to the debate on the pros and cons of accreditation is to be welcomed, but I am not sure that Dr Gill's notice does full justice to the complexities of the issue.

In most other specialties some form of certificate of completion of specialist training is issued by the appropriate College or Joint Committee, and the debate in other Colleges tends to be about the question of whether such a certificate should be given automatically on completing a fixed period of time in Senior Registrar posts or whether its issue should be subject to some further form of assessment or examination.

Psychiatrists have certainly not reached this point, and certain members of the JCHPT feel that the presence of College representatives on appointment committees for consultants is a sufficient safeguard for the public and will ensure that those becoming consultants are adequately trained. Those holding this view would certainly support the continuing inspection of training programmes in order to improve the quality of higher training experience available throughout the country.

Other members of the JCHPT feel that appointment committees for consultants do not provide sufficient guarantee of the quality of the individual candidate, and wish to see a formal accreditation certificate, particularly in the psychiatric specialties.

The Joint Committee has therefore set up a Work- ing Party on Accreditation with the following remit: 'To examine and report back to the Joint Committee on possible criteria for accreditation, and procedural questions implied by them, after consultation with the Specialist Advisory Sub-Committees and other Higher Training Committees.'

The Working Party has met on several occasions and its preliminary views are now being studied by the five Specialist Advisory Sub-Committees.

We hope that should accreditation begin this will be a simple procedure for the majority of trainees who have held approved Senior Registrar or Honorary Senior Registrar posts for a period of three years. At the same time we wish to adopt a flexible approach to trainees who have had less orthodox programmes of training, and particularly those who have spent a substantial amount of time in whole-time research. We envisage no form of examination during the higher training period but expect that local committees will ensure that the trainees 'perform to the satisfaction of their supervisors'.

It is not yet clear whether new legislation will make a specialist register compulsory in this country, and this is the principal reason for the JCHPT postponing a decision to begin accreditation, despite the fact that this leaves us in a different position from most other branches of medicine.

G. C. TIMBury 